\title{
Hubungan Jenis Serangga Penyerbuk dengan Morfologi Bunga Pada Tanaman Tomat (Lycopersicon Esculentum Mill.) dan Sawi (Brassica Juncea Linn.)
}

\author{
Phika Ainnadya Hasan*1, Tri Atmowidi ${ }^{2}$ \\ ${ }^{1,2,3}$ Departemen Biologi, Institut Pertanian Bogor, Kampus Dramaga, Bogor, 16680 \\ e-mail: *1. phkhasan@gmail.com ㄹatmowidi@gmail.com
}

\begin{abstract}
Abstrak
Morfologi bunga merupakan salah satu faktor yang mempengaruhi jenis serangga penyerbuk yang dapat berkunjung. Pengamatan dilakukan pada tomat Lycopersicon esculentum Mill dan tanaman sawi Brassica juncea Linn yang memiliki perbedaan pada bentuk bunga, khususnya pada bentuk benangsarinya. Pengamatan jenis serangga dilakukan selama sepuluh hari di lahan pertanian organik dengan menggunakan metode scan sampling. Pengamatan morfologi bunga meliputi bentuk, ukuran, warna dan struktur bunga. Ditemukan delapan spesies serangga sebagai penyerbuk pada kedua tanaman ini, yaitu Ceratina sp., Xylocopa confuse, Amegilla sp., Nomia sp., Megachile sp., Syrphus sp., Vanessa sp. Dan Hypolimnas sp. Namun hanya empat spesies yang diamati berkunjung pada tanaman tomat, yaitu Ceratina sp., Xylocopa confusa, Amegilla sp. dan Nomia sp. Spesies yang berkunjung pada kedua tanaman ini juga memperlihatkan perilaku yang berbeda dalam mengambil pollen dan nektar bunga.
\end{abstract}

Kata kunci: morfologi bunga, serangga penyerbuk, tomat, sawi

\section{PENDAHULUAN}

Serangga dan tanaman berbunga (angiospermae) merupakan dua kelompok makhluk hidup dengan tingkat keanekaragaman paling tinggi di bumi. Keanekaragaman mereka yang tinggi membentuk banyak jenis interaksi, salah satunya adalah interaksi tanaman berbunga dengan serangga penyerbuk. Tidak semua serangga adalah penyerbuk, dan tidak semua serangga penyerbuk mampu mengunjungi semua jenis bunga. Bentuk, warna dan ukuran bunga merupakan salah satu penarik serangga pada bunga (Faegri dan Pjil 1971). Karakter tersebut juga akan menentukan jenis serangga penyerbuk serta perilaku kunjungan serangga penyerbuk dalam mengambil polen ataupun nektar. Serangga penyerbuk dengan jenis yang sama bisa saja memiliki perilaku yang berbeda dalam mengambil nektar atau polen pada bunga dengan bentuk yang berbeda.

Peran serangga penyerbuk pada tomat dan sawi telah diketahui secara luas. Atmowidi (2008) melaporkan terjadi peningkatan jumlah polong pertanaman, jumlah biji per polong dan jumlah biji pertanaman masing-masing sebesar 179\%, 98\% dan 932\% pada tanaman caisin yang 
JURNAL SAINTIFIK VOL.3 NO.1, JANUARI 2017

penyerbukan dibantu oleh serangga. Sedangkan Al-Abbadi (2010) melaporkan peningkatan produksi tomat yang penyerbukannya dibantu oleh lebah (72\%) lebih tinggi daripada penyerbukan tanpa lebah (35\%).

Tomat dan sawi memiliki mahkota bunga berwarna kuning. Tetapi, dengan bentuk putik (pistil) dan benang sari (stamen) yang berbeda. Pada tanaman tomat, benangsari bergabung membentuk kerucut (cone) yang bersama-sama membungkus putik membentuk anthercone (Morse 2009). Sedangkan pada tanaman sawi, terdapat satu putik dan enam benang sari yang tidak terbungkus. Penelitian ini bertujuan untuk melihat hubungan pengaruh morfologi bunga terhadap jenis serangga penyerbuk yang berkunjung serta perilaku kunjungan mereka pada tanaman tomat dan sawi.

\section{METODE PENELITIAN}

\section{Waktu dan Tempat Pengamatan}

Pengamatan dilakukan selama sepuluh hari (masing-masing lima hari untuk satu jenis tanaman) pada bulan September, Oktober dan November 2014. Berlokasi di lahan pertanian organik Bina Sarana Bakti, Cisarua, Bogor. Identifikasi serangga penyerbuk dilakukan di Laboratorium Entomologi, LIPI, Cibinong, Bogor.

\section{Pengamatan Morfologi Bunga}

Pengamatan morfologi bunga meliputi bentuk, jumlah dan letak benang sari dan putik serta bentuk, warna dan ukuran bunga. Pengukuran diameter bunga dilakukan dengan menggunakan jangka sorong sebanyak lima bunga untuk setiap jenis bunga. Pengamatan putik dan benangsari dilakukan dengan bantuan mikroskop. Analisis data dilakukan secara deskriptif.

\section{Pengamatan Keanekaragaman Serangga Penyerbuk}

Pengamatan dilakukan dengan metode scan sampling (Martin dan Bateson 1993), pada tanggal 19,20,22,23 September dan 1 Oktober 2014 (pada tanaman sawi) dan pada tanggal 25,26,27 Oktober dan 1-2 November 2014 (pada tanaman tomat). Pengamatan meliputi jenis dan jumlah serangga penyerbuk pada pukul 07.00-12.00 saat cuaca cerah. Pengamatan dilakukan selama 15 menit setiap jam selama pengamatan. Pengkoleksian serangga penyerbuk yang belum diketahui jenisnya menggunakan insect net dan selanjutnya dilakukan preservasi dengan metode standar, menggunakan etanol $70 \%$ atau kertas papilot, untuk selanjutnya dibawa ke laboratorium untuk di identifikasi. Identifikasi serangga penyerbuk dilakukan dengan membandingkan sampel dengan spesimen yang terdapat di Museum Zoologicum Bogoriense, LIPI, Cibinong atau merujuk pada Michener (2000), Borror dan Delong (1964) dan Tsukada (1985). Analisis data keanekaragaman dilakukan dengan menghitung indeks keanekaragaman Shannon-Wiener (H') dan indeks kemerataan (E).

\section{Pengamatan Perilaku Kunjungan Serangga Penyerbuk}

Pengamatan perilaku kunjungan menggunakan metode focal sampling (Martin dan Bateson 1993) selama lima hari untuk masing-masing tanaman pada bulan September dan Oktober 2014. Pengamatan dilakukan pada semua serangga penyerbuk tanaman tomat san wi pada pukul 07.00-12.00 WIB. Pengamatan meliputi waktu serangga penyerbuk memulai foraging dan perilaku mengambil nektar dan polen. Analisis data dilakukan secara deskriptif. 


\section{HASIL DAN PEMBAHASAN}

Dua spesies tanaman dengan morfologi bunga yang berbeda digunakan dalam penelitian ini, yaitu tanaman tomat (Lycopersicon esculentum Mill.) dan sawi (Brassica juncea Linn.). hal ini diharapkan dapat menjadi pembanding untuk melihat hubungan morfologi bunga dengan jenis serangga penyerbuk. Bunga tomat berwarna kuning dengan jumlah mahkota 5-6 tergantung jenisnya. Bunga tomat memiliki satu putik yang dikelilingi banyak benang sari dan bersama-sama terbungkus oleh kepala sari. Rata-rata lima diameter bunga yang diukur adalah $21.91 \mathrm{~mm}$ (Gambar 1).
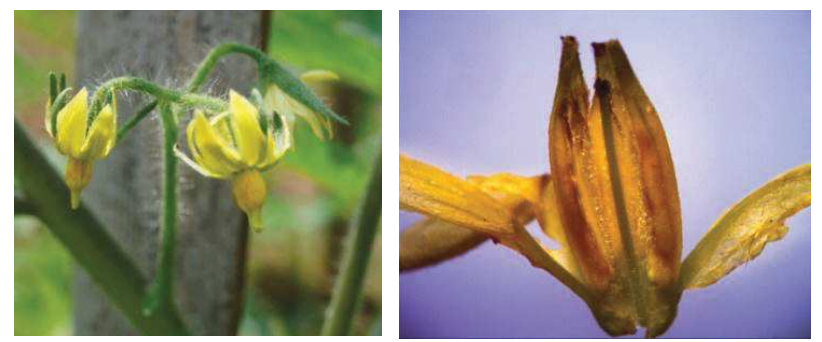

Gambar 1 Bunga tomat

Bunga sawi memiliki empat mahkota yang berwarna kuning. Memiliki enam benang sari dan satu putik. Empat benang sarinya lebih panjang dari dua benang sari lainnya. Bunga sawi tersusun dalam tandan dengan rata-rata diameter dari lima bunga yang diukur adalah $15.9 \mathrm{~mm}$ (Gambar 2).
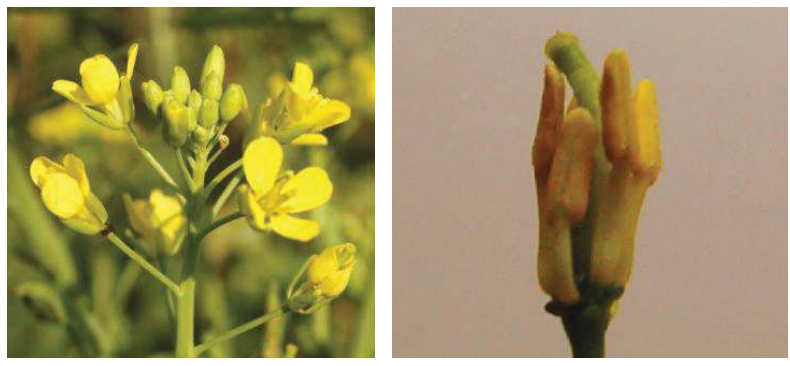

Gambar 2 Bunga sawi

Total terdapat delapan spesies serangga penyerbuk yang diamati dalam penelitian ini. Hasil pengamatan menunjukan adanya perbedaan jenis serangga penyerbuk pada tanaman tomat dan sawi. Pada tanaman sawi yang putik dan benangsarinya terbuka, serangga penyerbuknya lebih umum, yaitu terdapat 8 spesies, 6 famili dan 3 ordo, yaitu Ceratina sp., X. confusa, Amegilla sp., Nomia sp., Megachile sp., Syrphus sp., Vanessa sp. dan Hypolimnas sp. Sedangkan pada tomat, yang putik dan benangsarinya terbungkus dalam anthercone terdapat hanya terdapat 4 spesies, 2 famili dan 1 ordo serangga penyerbuk, yaitu Ceratina sp., X. confusa, Amegilla sp., Nomia sp. (Tabel 1). 
JURNAL SAINTIFIK VOL.3 NO.1, JANUARI 2017

Tabel 1 Perbandingan jenis serangga penyerbuk sawi dan tomat

\begin{tabular}{|c|l|c|c|c|c|}
\hline No. & Jenis Penyerbuk & Sawi & Tomat & Famili & Ordo \\
\hline 1. & Ceratina sp. & V & V & Apidae & Hymenoptera $^{1}$ \\
\hline 2. & Xylocopa confusa & V & V & Apidae & Hymenoptera $^{1}$ \\
\hline 3. & Amegilla sp. & - & V & Apidae & Hymenoptera $^{1}$ \\
\hline 4. & Nomia sp. & - & V & Halictidae & Hymenoptera $^{1}$ \\
\hline 5. & Megachile sp. & V & - & Megachilidae & Hymenoptera $^{1}$ \\
\hline 6. & Syrphus sp. & V & - & Shyrpidae & Diptera $^{2}$ \\
\hline 7. & Vaness sp. & V & - & Nymphalidae & Lepidoptera $^{2}$ \\
\hline 8. & Hypolimnas sp. & V & - & Danaidae & Lepidoptera $^{2}$ \\
\hline
\end{tabular}

Sumber : ${ }^{1}$ Michener 2007; ${ }^{2}$ Borror dan Delong 1964.

Perbedaan morfologi bunga juga diduga menjadi penyebab adanya perbedaan indeks keanekaragaman. Indeks keanekaragaman, total individu dan total spesies serangga penyerbuk pada tanaman sawi (1.51) lebih tinggi dari pada tanaman tomat (1.23). Spesies serangga penyerbuk yang dominan pada tanaman sawi adalah Megachile sp. sedangkan pada tanaman tomat adalah $X$. confusa (Tabel 2).

Tabel 2 Keanekaragaman serangga penyerbuk

\begin{tabular}{|c|c|c|c|c|c|}
\hline \multirow[t]{2}{*}{ No. } & \multirow[t]{2}{*}{ Jenis Penyerbuk } & \multicolumn{4}{|c|}{ Jumlah Individu } \\
\hline & & Sawi & $\begin{array}{c}\text { Persentase } \\
(\%)\end{array}$ & Tomat & $\begin{array}{c}\text { Persentase } \\
(\%)\end{array}$ \\
\hline 1. & Ceratina $\mathrm{sp}$. & 8 & $7.07 \%$ & 9 & $13.84 \%$ \\
\hline 2. & Xylocopa confusa & 11 & $9.73 \%$ & 29 & $44.61 \%$ \\
\hline 3. & Amegilla sp. & - & - & 20 & $30.76 \%$ \\
\hline 4. & Nomia sp. & - & - & 9 & $7.96 \%$ \\
\hline 5. & Megachile sp. & 32 & $28.31 \%$ & - & - \\
\hline 6. & Shyrpidae & 9 & $7.96 \%$ & - & - \\
\hline 7. & Vanessa sp. & 9 & $7.96 \%$ & - & - \\
\hline 8. & Hypolimnas sp. & 2 & $1.76 \%$ & - & - \\
\hline & Total Individu & \multicolumn{2}{|c|}{113} & \multicolumn{2}{|c|}{65} \\
\hline & Total spesies & \multicolumn{2}{|r|}{6} & \multicolumn{2}{|r|}{4} \\
\hline \multicolumn{2}{|c|}{ Indeks keanekaragaman (H') } & \multicolumn{2}{|c|}{1.51} & \multicolumn{2}{|c|}{1.23} \\
\hline & Kemerataan (E) & \multicolumn{2}{|c|}{0.78} & \multicolumn{2}{|c|}{0.89} \\
\hline
\end{tabular}

Penelitian sebelumnya juga telah melaporkan beberapa spesies dalam penelitian ini sebagai serangga pengunjung tanaman sawi dan tomat. Ceratina sp., X. confusa, Nomia sp. merupakan serangga penyerbuk pada tanaman sawi (Brassica rapa) (Atmowidi 2008), Amegilla spp. merupakan serangga penyerbuk tanaman sawi (Brassica juncea) (Kunjwal et al. 2014) dan tomat (Hogendoorn et al. 2006) serta Megachile spp. merupakan serangga penyerbuk tanaman sawi (Kunjwal et al. 2014) dan tomat (Kasina et al. 2009).

Berdasarkan pengamatan, genus Xylocopa, khususnya $X$. confusa dapat digolongkan sebagai penyerbuk generalis. Sebab, selain mengunjungi sawi dan tomat, spesies ini juga terlihat mengunjungi tanaman lain seperti kemangi, kapri dan mentimun, yang ketiga tanaman tersebut memiliki perbedaan bentuk dan ukuran bunga. 
Spektrum warna pada serangga berbeda dengan manusia. Tiga sperktrum warna utama pada manusia adalah biru-ungu, hijau dan merah sedangkan pada lebah ultraviolet, biru dan kuning (Barth 1991). Dua jenis tanaman yang digunakan dalam penelitian ini keduanya berwarna kuning dan serangga yang berkunjung adalah dari ordo Hymenoptera, Diptera dan Lepidoptera. Dengan demikian, ketiga ordo tersebut dapat mengunjungi bunga-bunga yang berwarna kuning. Dalam pengamatan juga terlihat bahwa $X$. confusa, juga terlihat mengunjungi bunga dari famili papilionaceae yakni kapri yang berwarna ungu dan famili cucurbitaceae yakni mentimun yang berwarna kuning. Sedangkan Ceratina sp. terlihat mengunjungi bunga mentimun dan kemangi yang berwarna putih.

Selain perbedaan jenis serangga penyerbuk, perilaku kunjungan spesies serangga penyerbuk juga berbeda pada kedua tanaman ini. Pada tanaman sawi, Megachile sp. terlihat mulai berkunjung pada pukul 07.00 WIB sedangkan Ceratina sp. Vanessa sp. dan Hypolimnas sp. memulai kunjungan pada pukul 09.00 WIB. Pada tanaman tomat, Xylocopa confusa memulai kunjungannya pada pukul 07.00 WIB. Selain itu, perbedaan perilaku kunjungan juga terlihat pada cara serangga penyerbuk mengambil nectar dan polen.

Perbedaan jelas terlihat pada model penyerbukan dua tanaman tersebut. Penyerbukan pada sawi adalah yang umum terjadi. Serangga mendarat di bunga lalu menjulurkan proboscisnya untuk menghisap nektar atau menggunakan tungkai mereka untuk mengumpulkan polen (Gambar 3). Penyerbukan yang terjadi pada tomat dikenal sebagai buzz pollination, yakni penyerbukan dengan cara menggetarkan bunga tomat sehingga pollennya jatuh (Barth 1991). Serangga akan hinggap di bunga lalu menggetarkannya dan mengumpulkan polennya (Gambar 4). Menurut Barth (1991), getaran pada tubuh serangga di hasilkan oleh kontraksi otot terbang. Namun gerakan tersebut bukan untuk terbang, tetapi gerakan tersebut diubah menjadi getaran dan di transfer ke bunga melalui tungkai.

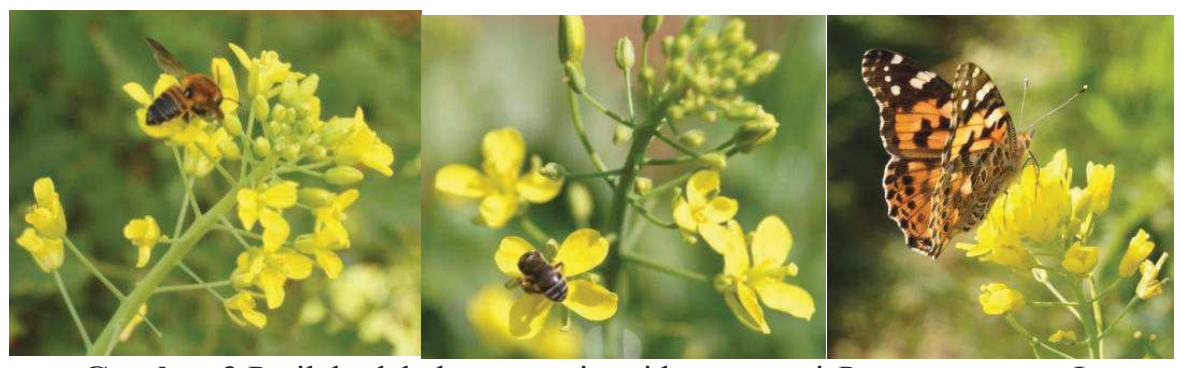

Gambar 3 Perilaku lebah mengunjungi bunga sawi Brassica juncea L.

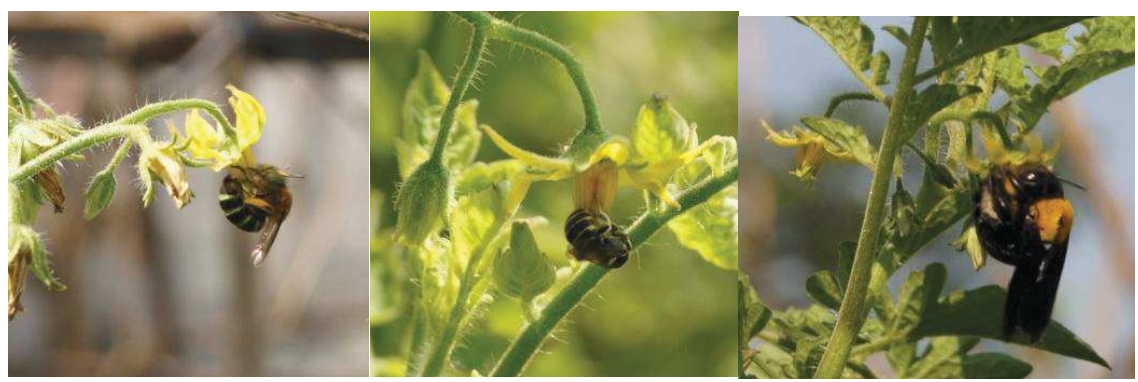

Gambar 4 Perilaku lebah mengunjungi bunga tomat Lycopersicon esculentum M. 
JURNAL SAINTIFIK VOL.3 NO.1, JANUARI 2017

\section{KESIMPULAN}

Terdapat hubungan antara morfologi bunga dengan jenis serangga penyerbuk yang berkunjung. Pada tanaman sawi terdapat enam spesies serangga penyerbuk, yaitu Ceratina sp., Xylocopa confusa, Megachile sp., Vanessa sp., Danaus sp. Syrphus sp. Sedangkan pada tanaman tomat hanya terdapat empat spesies, yaitu Xylocopa confusa, Amegilla sp., Ceratina sp., dan Nomia sp.

\section{DAFTAR PUSTAKA}

Al-Abbadi, SY., 2010, Open Pollination Efficiency on Field-Grown Tomato Compared with Isolated Under Similar Condition, Sarhad J. Agric., No.26, Vol.3.

Atmowidi, T., 2008, Keanekaragaman dan Perilaku Kunjungan Serangga Penyerbuk serta Pengaruhnya Terhadap Pembentukan Biji Tanaman Caisin (Brassica rapa L.: Brassicaceae), Disertasi, Program Pasca Sarjana, Institut Pertanian Bogor, Bogor.

Barth, FG., 1991, Insect and Flowers: The Biology of Partnership, Princeton University Press, New Jersey.

Borror, DJ., Delong, DM., 1964, An Introduction to The Study of Insects, Holt, Rinehart and Winston, New York.

Faegri, K., van der Pjil L., 1971, The Principles of Pollination Ecology, Pergamon Press, New York.

Hogendoorn, K., Gross, CL., Sedgley, M., Keller, MA., 2006, Increased Tomato Yield Through Pollination by Native Australian Amegilla chlorocyanea (Hymenoptera: Anthophoridae) [abstrak]. Journal of Economic Entomology, No.99, Vo.3, Hal.828-833.

Kasina, M., Hagen, M., Kraeme, M., Nderitu, J., Martius, C., Wittmann, D., 2009, Bee Pollination Enhances Crop Yield and Friut Quality in Kakamega, Western Kenya [abstrak], University of Nairobi, Kenya.

Martin, P., Bateson P., 1993, Measuring Behavior, Cambridge University Press, Cambridge.

Michener CD., 2007, The Bees of The World second edition, The Johns Hopkins University Press, Maryland.

Morse, A., 2009, Floral Scent and Pollination of Greenhouse Tomatoes, Thesis, The Univeristy of Guelph, Canada.

Tsukada, E, 1985, Butterflies of The South East Asian Island IV Nymphalidae (I), PLAPAC Co., Ltd., Tokyo. 